\title{
TALLERES DE ARTE DE RECICLAJE CON MATERIALES HOSPITALARIOS ${ }^{1}$
}

\section{Recycling hospital materials into art workshop}

\author{
$M^{\mathrm{a}}$ DEL CARMEN MoReno \\ Universidad Complutense de Madrid \\ cmorenosaez@art.ucm.es \\ Ma Jesús ABAD \\ Ces Felipe II Aranjuez \\ mjabad@cesfelipesegundo.com \\ LORENA LÓPEZ \\ Universidad de Salamanca \\ lorenalopezmendez@gmail.com
}

Recibido: 12 de abril 2011

Aprobado: 6 de mayo de 2011

\begin{abstract}
Resumen:
En las Unidades de Diálisis y Oncología del Hospital Gregorio Marañón se ha llevado a cabo un taller denominado "Soy un super héroe", destinado a niños y adolescentes que tienen que acudir periódicamente a este Centro y que consiste en la realización de una escultura-juguete realizada con algunos objetos reciclados de uso hospitalario. Este taller ha servido de base para idear la propuesta "Pecera Yayoi" fundamentada en las estéticas de la artista japonesa Yayoi Kusama con la finalidad de construir piezas visuales -cristalizadas en una pecera- que permiten al paciente establecer múltiples formas de relación con el arte contemporáneo, la contemplación de una pieza artística realizada por si mismo y, finalmente, la satisfacción de compartir un conocimiento. Pensamos que es una buena manera no sólo de hacer más agradable el tiempo que deben permanecer en el Hospital sino que, además, contribuye a la conservación del medio ambiente y a la difusión del Arte Contemporáneo. Palabras clave: Material hospitalario, Reciclaje, Arte Contemporáneo, Escultura.
\end{abstract}

Moreno, C. Abad, J. López, L 2011: Talleres de arte de reciclaje con materiales hospitalarios. Arte, Individuo y Sociedad, Vol. 23, Núm. Especial, 135- 152

\begin{abstract}
:
A workshop called "I'm a super hero" has been carried out for children and teens that have to go regularly to the Dialysis Units and Oncology wards of the Gregorio Marañón Hospital. The workshop consists of creating toy-sculptures made with recycled hospital equipment. This workshop has been useful to carry out the "Yayoi Fishbowl" proposal, based on the aesthetics of Japanese artist Yayoi Kusama, building visual-crystallized pieces in a fishbowl, letting the patient create multiple forms of relationship with Contemporary Art, the contemplation of artwork by itself and, finally, the satisfaction of sharing knowledge. We think it's a better way for patients to spend their time at the Hospital, and it also contributes to environment preservation and diffusion of Contemporary Art.

Key words: Hospital equipment, Recycling, Contemporary Art, Sculpture.
\end{abstract}

Sumario: 1. Introducción, 2. Taller "Soy un superhéroe", 3. Taller acuario "Yayoi". Referencias.

1 Esta investigación ha sido financiada por el Ministerio de Ciencia e Innovación (EDU200805441-C02-00/EDU) 


\section{Introducción}

En las Unidades de Diálisis y Oncología del Hospital Gregorio Marañón se ha llevado a cabo un taller denominado "Soy un super héroe", que consiste en la realización de una escultura-juguete realizada con algunos objetos de uso hospitalario. Este taller ha servido de base para idear la propuesta "Pecera Yayoi" fundamentada en las estéticas de la artista japonesa Yayoi Kusama con la finalidad de construir piezas visuales -cristalizadas en una pecera- que permiten al paciente establecer múltiples formas de relación con el arte contemporáneo, la contemplación de una pieza artística realizada por si mismo y, finalmente, la satisfacción de compartir un conocimiento.

\section{Taller "Soy un superhéroe"}

\subsection{Bio}

El taller se ha realizado durante los meses de junio y julio de 2010. Partiendo de términos como Reciclaje y Ecología, conceptos que nos son familiares, se plantea la creación de esculturas de pequeño formato con objetos y utillaje hospitalario, pudiendo ser "readymade" u "objet trouvé". Estos términos hacen referencia a lo que se conoce como Arte Encontrado, que nos describe las obras realizadas mediante el uso de objetos que no tienen una función específicamente artística, pero que se modifican o se recontextualizan para conseguir tal fin y cuyo creador fue Marcel Duchamp a principios del siglo XX.

El hecho de transformar materiales que pierden su función y que desechamos y convertirlos en "arte", plantea una búsqueda que en la actualidad es perseguida por diferentes colectrivos artísticos y diversos grupos de defensores del medio ambiente. Aunque la práctica del reciclaje es muy antigua, la denominación del término es relativamente reciente y se relaciona con los avances en los estudios sobre las problemáticas ecológicas o medioambientales, remitiéndonos al proceso de reutilización de los objetos y materiales que se encuentran en el entorno.

En nuestro taller, se pretende que a través del reciclaje de utensilios hospitalarios, los participantes puedan conocer y valorar otras funciones que puede tener ese material, construyendo una serie de esculturas de pequeño formato, a modo de collage, de objetos, de tal manera que adquieran una conducta ecológica de respeto al medio ambiente fomentando su conservación.

El taller se ha diseñado teniendo en cuenta la especificidad de las Unidades de Diálisis y Oncología, en las que nos podemos encontrar con diversas patologías, debido a los estadios en que se encuentra la enfermedad de los pacientes, los tratamientos a que son sometidos y las estancias prolongadas o intermitentes que tienen que afrontar. 


\subsection{Objetivos educativos}

Con este taller, pretendemos que los alumnos no sólo sean capaces de:

- Reflexionar sobre las sensaciones que nos aporta el utillaje hospitalario.

- Encontrar nuevas aplicaciones en los materiales que habitualmente encuentran en su entorno de hospitalización.

- Experimentar un nuevo uso de estos materiales y neutralizando las posturas de rechazo o de temor frente a los mismos.

- Diseñar un objeto de pequeñas dimensiones con materiales de desecho hospitalario.

- Recontextualizar un objeto y modificarlo para que pueda ser contemplado desde diferentes puntos de vista.

- Dirigir su propia producción y aprender a tomar decisiones para resolver los problemas que puedan presentarse.

- Conocer diferentes versiones de artistas contemporáneos que establecer un juego visual con objetos encontrados.

- Sensibilizarse con el medio ambiente, reciclando materiales y dándoles un uso diferente.

- Trabajar en equipo, respetando las opiniones de los demás.

\subsection{Contenidos}

El taller consta de una parte teórica y otra parte práctica; la parte teórica, presentada en Power Point, consistirá en la proyección de los trabajos de diferentes artistas que en la actualidad están realizando sus obras en materiales de reciclaje. En cuanto a la práctica, los asistentes desarrollarán una serie de esculturas de pequeño formato con objetos y utillaje hospitalario.

\subsection{Bloque teórico}

A través de un Power Point se presenta la obra de los artistas Joan Brosa, Chema Madoz, Victoria Encinas y Liliana Porter, describiendo el medio en el que trabajan, así como los materiales utilizados para la consecución de sus obras.

\subsection{Bloque práctico}

Debido a la especifidad del contexto y del público a quien va dirigido, con este taller pretendemos que los pacientes aprendan a ver, conectar con los demás y generar su propio conocimiento, suscitando su interés por la obra artística y el arte contemporáneo, el cual posee una enorme transcendencia formativa, no sólo porque habla de la realidad actual, sino porque proporciona conceptos y pautas que nos ayudan comprender e interpretar el mundo que nos rodea.

Sirviéndonos de una serie de materiales de fácil acceso en un hospital por su utilización diaria y cedido por personal sanitario, como pueden ser jeringuillas, palillos, gasas, tiritas y otros, procederemos a darles nuevas funcionalidades, además las que ya poseen y para las que fueron creadas. 


\subsection{Desarrollo de los contenidos}

Los contenidos se desarrollarán de la siguiente forma:

1. Punto de partida de la propuesta de trabajo

Hemos comenzado el taller con el visionado del tráiler de la película "Toy Story 3". Consideramos que es muy interesante el comienzo del taller con una película o serie conocida por los niños, en este caso de dibujos animados, cuyos personajes son juguetes.

A partir de este sketch comenzaremos a reflexionar sobre el número de juguetes que tienen cada uno de los asistentes y planteamos la posibilidad de diseñar sus propios juguetes con materiales reciclados, además de analizar cada uno de los personajes que aparecen.

\section{Preguntas clave}

Tras el visionado, iniciamos con los niños un debate a partir de una serie de preguntas que hemos denominado preguntas clave y que que nos han permitido poner sobre la mesa sus prejuicios, estereotipos y reflexiones relacionados con sus experiencias y conocimientos previos acerca de sus propios juguetes

- ¿Los dibujos animados, pueden ser ARTE?

- ¿Qué habéis visto sobre Arte Contemporáneo en los anteriores talleres?

\subsection{Presentación de artistas contemporáneos}

El primero de los artistas de referencia es Joan Brossa, quien intenta descubrir la magia en el objeto más cotidiano combinandolo con la poesía. En sus obras existe un fuerte contraste entre el título y el objeto recontextualizado que realiza.

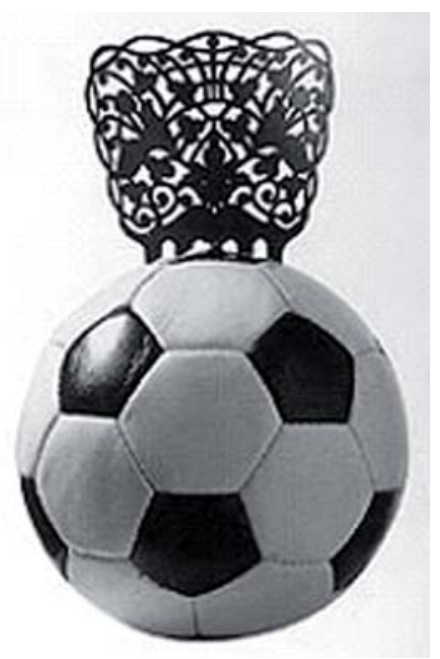

Fig.1. Joan Brossa. País.

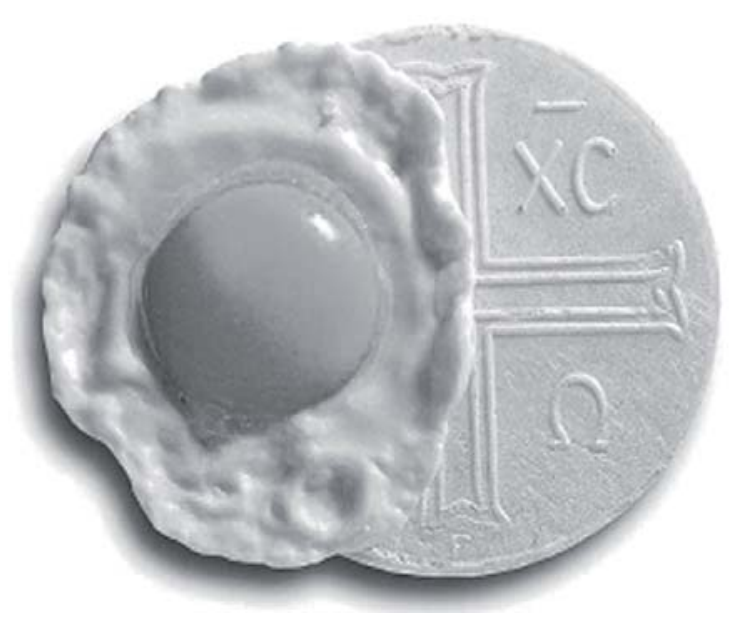

Fig.2. Joan Brossa. Eclipse. 
Otro de los referentes para los alumnos es la obra Chema Madoz, quien se centra en el universo de los objetos, las apariencias múltiples, las asociaciones y los juegos de relaciones iconográficas, en los que la poesía objetual y la memoria del surrealismo se encuentran siempre presentes y configuran un universo muy particular cargado de referencias cruzadas y metáforas.
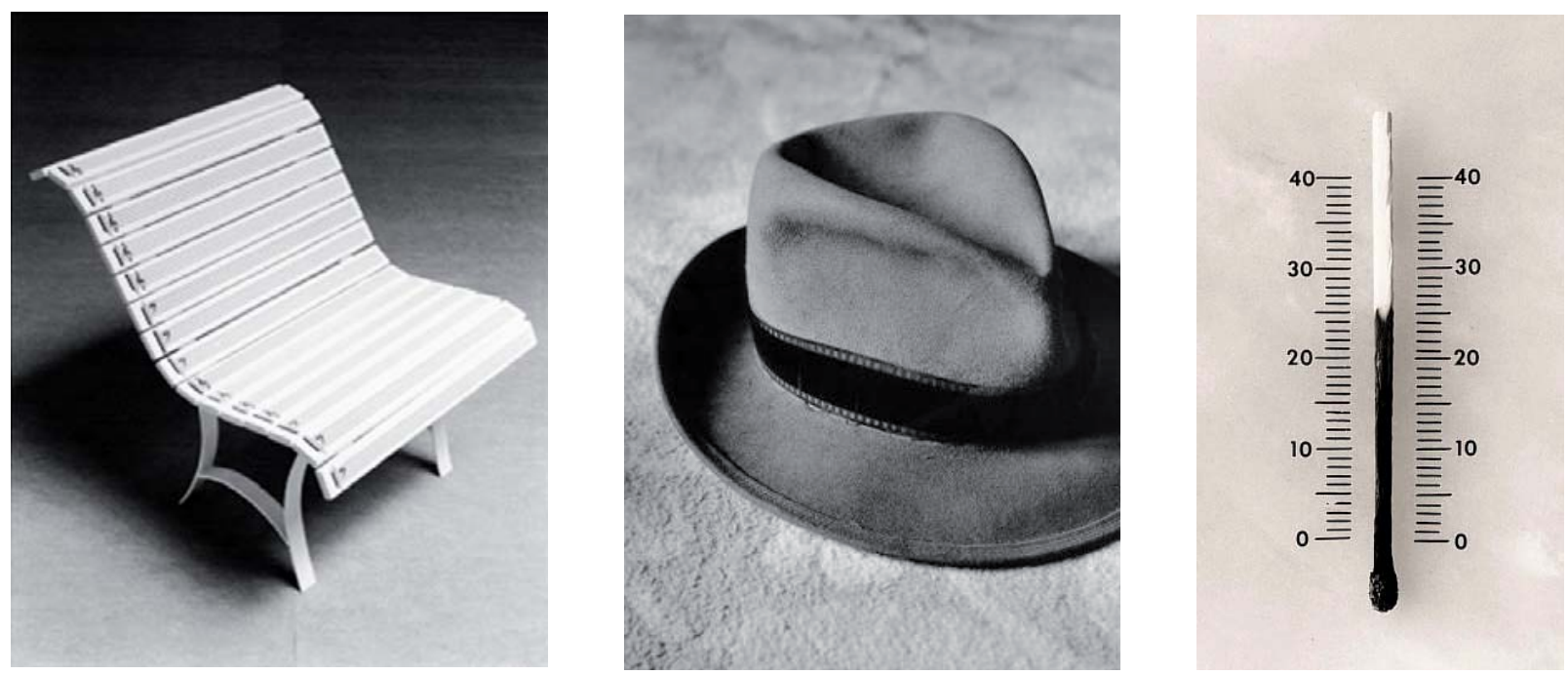

Fig.3,4,5. Chema Madoz

Uno de los ejemplos más claros de reciclaje en el arte lo encontramos de la mano de Victoria Encinas, quien interrelaciona la pintura con la fotografía y la arquitectura con los objetos. Su búsqueda se basa en conseguir el orden geométrico-espiritual. Realiza su obra utlizando diferentes objetos reciclados, que combina la lógica minimalista con el ligero humor de su mirada.

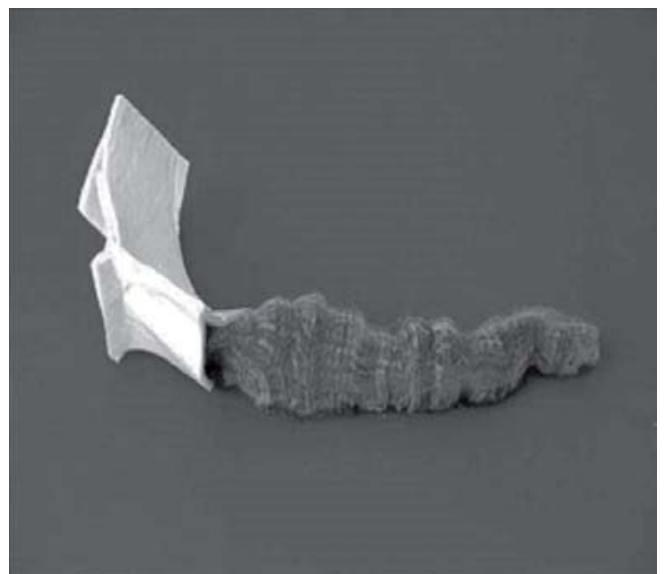

Fig.6. Victoria Encinas. Micro.

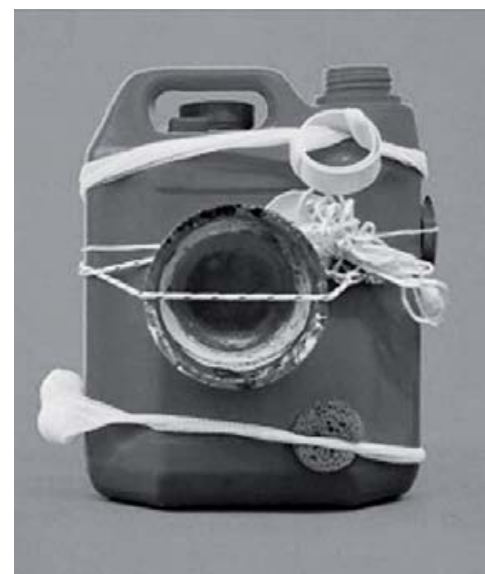

Fig.7. Victoria Encinas. Refugiados 3.

Por último hemos proyectado a los alumnos imágenes de la obra de Liliana Porter, que trabaja básicamente con juguetes, muñecos y fotografías. Esta artista argentina es un claro ejemplo de cómo un material cotidiano se puede combinar con otros reci- 
clados, recreando nuevos objetos.

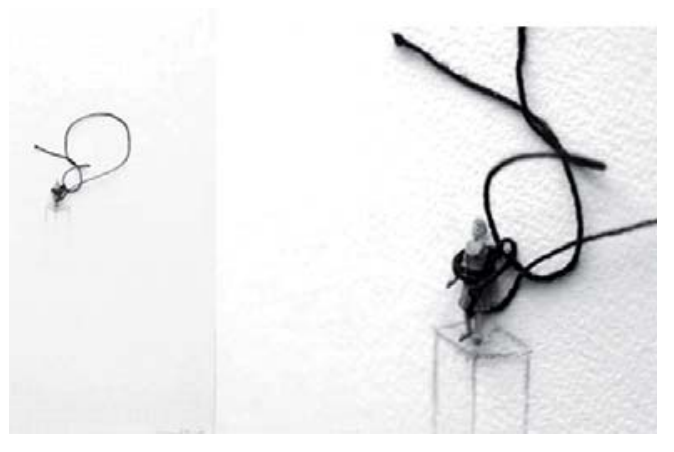

Fig.8. Liliana Porter. Black rope.

\subsection{Propuesta de trabajo}

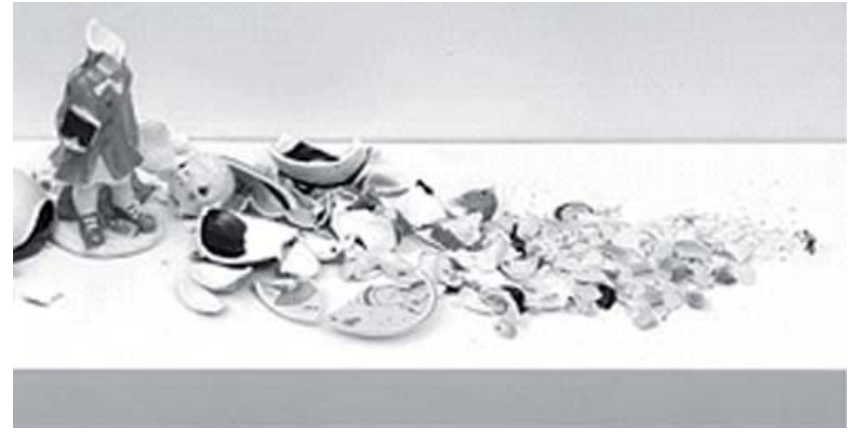

Fig.9. Liliana Porter. Forced labor.

Finalmente los asistentes realizaron su propia producción mediante el empleo del reciclaje de una serie de materiales e instrumental de uso hospitalario, con el fin de crear una pequeña escultura-juguete con la que, de alguna forma, se han identidicado. La propuesta se planteó de la siguiente manera:

1. ¡Realicemos nuestro propio juguete!

2. ¿Con qué materiales creéis que es conveniente hacerlo?

3. ¿ Por qué habéis elegido esos materiales?

4. ¿Cómo podrías construirlo?

Los resultados que obtuvimos tras nuestra propuesta fueron los siguientes:
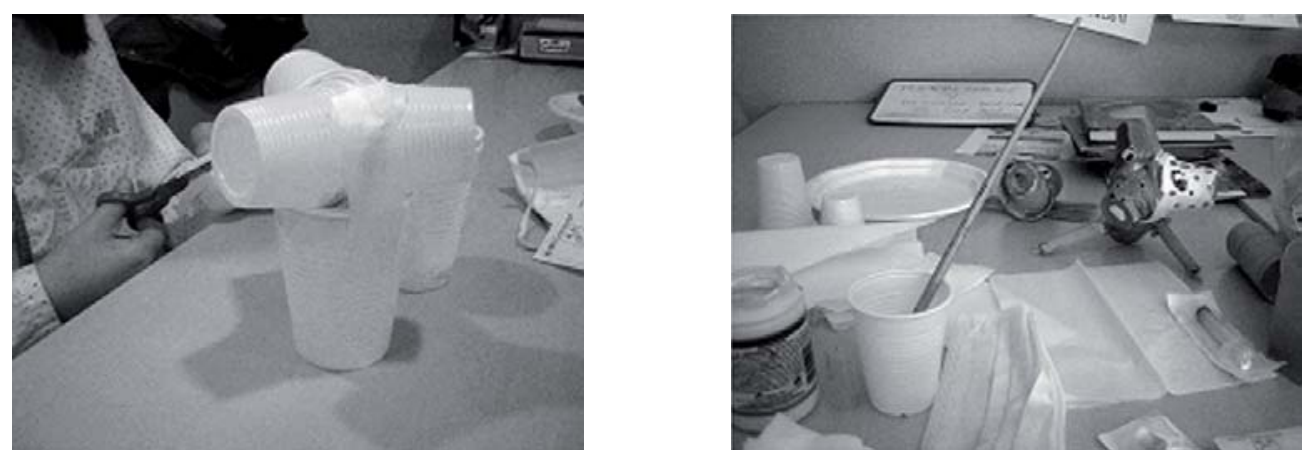

Fig.10,11. Proceso de trabajo Clara.

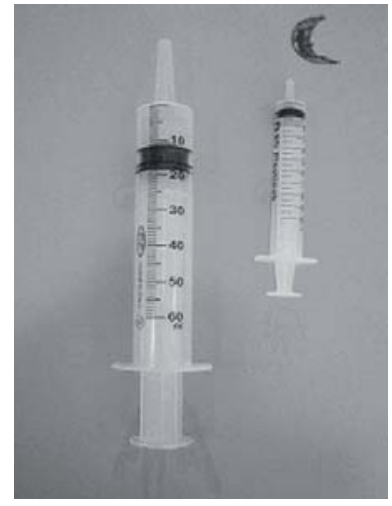

Fig.12. Al Espacio . Jonathan. 15 años.

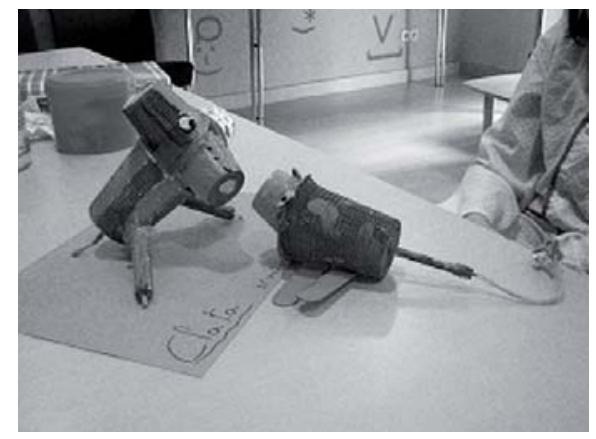

Fig.13. Zoomorfos. Clara. 11 años. 


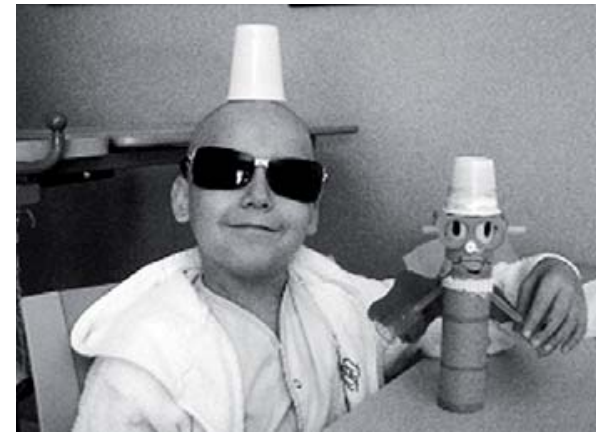

Fig.14. Antonio. 9 años.

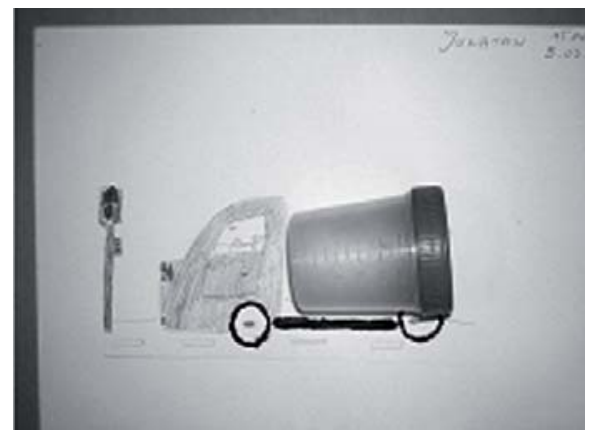

Fig.15. Camión. Jonathan. 15 años.

\subsection{Puesta en común}

Una vez finalizado el taller, se realizó una pequeña exposición de los juguetes creados por los asistentes, a la que podían acceder sus familiares, compañeros y el propio personal de la unidad. La materialización de los trabajos ha permitido que los pacientes no sólo se hayan interesado por la realización de sus obras sino que, también, abren nuevas vías de ampliación de su particular colección.

\subsection{Conclusiones del taller "Soy un superhéroe"}

La transformación de materiales de uso hospitalario proporciona a los participantes no sólo nuevos retos en cuanto a la elección del utillaje a emplear, sino que, también les conecta con una experiencia artística y una conciencia ecológica.

La realización de una escultura-juguete de pequeño tamaño, realizada con material hospitalario, amplía las posibilidades de representación de un personaje o de un juguete específico, donde el paciente tiene que valorar su durabilidad u otras posibles funciones diferentes de las que inicialmente tenían.

La búsqueda de nuevas soluciones estéticas a partir de un material reciclado, desarrolla la creatividad de los asistentes, animándoles en la búsqueda de otros materiales, valorando y respetando el medio ambiente.

El desarrollo del taller con más de un participante facilita la comunicación entre los pacientes y les anima a trabajar de forma cooperativa, aportando nuevas ideas y respetando las opiniones de los demás, dando lugar a debates posteriores.

\section{Taller Acuario "Yayoi"}

\subsection{Introducción}

Se propone la realización de este taller para construir un pequeño acuario partiendo de las bolsas que se utilizan en los hospitales para suministrar medicación intravenosa y otros materiales de fácil manipulación y acceso.

Se trata de reutilizar materiales de desecho que se pueden encontrar en el ámbito 
hospitalario, para construir pintando o recortando formas -que recuerden a peces- $y$ fondos también intervenidos, con el propósito de hacer una "pecera" basada en las estéticas de la artista japonesa Yayoi Kusama.

Este módulo se puede realizar en dos o tres sesiones de 2 horas cada una. Teniendo en cuenta las características de los pacientes, se pone a disposición del educador la idea germinal, para que, haciéndola "suya" pueda impartirla ajustándola a las circunstancias. Es válida para cualquier edad siendo la más apropiada entre los 10 y 16 años. Puede adaptarse a todas la edades.

\subsection{Objetivos}

Para transmitir conocimiento es preciso fijarse unos objetivos claros que respondan a las expectativas del docente -ideólogo, de la sociedad y de las personas a las que va orientado.

Los objetivos en educación artística se originan a partir de reflexiones que persiguen argumentar el "ideal" de una acción pedagógico-artística. Después, en la puesta en marcha de los enunciados, se trata de no perder la esencia de los puntos de partida, crear un clima intelectual valorizador de la propuesta y compartir saberes con creatividad y generosidad. Lo compartido es fundamental como bien que nos pertenece a todos cuestión que viene al caso en esta proposición, tan común y tan diferente, ya que se propone en una sociedad que se distingue por el consumo y se hace sin fines de lucro.

Desde este postulado concretamos los siguientes objetivos:

- Realizar una pecera con la estética derivada del conocimiento de la artista Yayoi Kusama.

- Mejorar la autoestima utilizando el arte como medio para encontrar respuestas satisfactorias en forma de piezas artísticas.

- Rentabilizar en forma de conocimiento el tiempo de ingreso hospitalario.

- Redirigir el pensamiento - generalmente centrado en la enfermedad- hacia la acción y la búsqueda de la belleza.

- Estimular la capacidad creativa creando nuevas relaciones entre los materiales que les rodean.

- Enriquecer el lenguaje visual de los asistentes.

- Desarrollar la capacidad manual de la mano operativa con apoyo de la libre (los niños de diálisis sólo disponen de una mano).

- Favorecer la creación de saberes compartidos.

\subsection{Metodología}

Asentada sobre tres pilares que se utilizan simultáneamente. Apuntar que no es necesario terminar el bloque teórico para empezar el debate al tiempo que se divulgan los resultados parciales del proceso en la red de Internet:

1. Teórico prácticos en formato de clase magistral con referencias visuales. 
Información teórica con información visual sobre la artista Yayoi Kusama. Explicación teórico-práctica sobre el uso de materiales hospitalarios para la realización de la pecera.

2. Discusión/debate sobre arte y artistas contemporáneos, formatos de trabajos artísticos.

3. Exposición y difusión de resultados. Si fuera posible exposición física en el hospital y, en todo caso, difusión a través de las redes sociales: Twitter, Blog, FaceBook...

\subsection{Contenidos}

Para conseguir los objetivos propuestos se articulan los contenidos bajo dos parámetros que a su vez se sirven de varias vías, que tratan de solaparse para acometer cada objetivo desde distintas perspectivas y así reforzar cada uno asegurándonos de que alcanzan sus metas.

Se contemplan los módulos teóricos y prácticos que vamos de los que damos cuenta a continuación.

\subsection{Bloque teórico}

- Clases teóricas con apoyo visual en los que se cuenta partiendo de imágenes de las acciones artísticas de Yayoi Kusma.

- Clase magistral apoyada en las líneas básicas para el conocimiento de la artista y que destacamos a continuación.

Yayoi es una artista japonesa multidisciplinar. Nacida en 1929, su manera de percibir el mundo se ha convertido en su marca de identidad: los puntos.

Yayoi vive en un sanatorio psiquiátrico muy cerca de su estudio. Pinta, esculpe, dirige cine, hace instalaciones, performances, compone música...todo desde su particular modo de ver el mundo. Su producción artística se ha visto condicionada debido a diferentes experiencias visuales que tuvo en su niñez. Considera que dicha experiencias la sitúan como una artista que sabe describir un mundo propio en soportes diferentes.

Una de las obsesiones de Yayoi es la representación del espacio infinito, creando laberintos visuales en los que el espectador siente el espacio transformado bajo parámetros a los que no está acostumbrado. Instalaciones en las que el espectador vive sensaciones nuevas que le impulsan a plantearse lo interminablemente infinito que puede ser. 


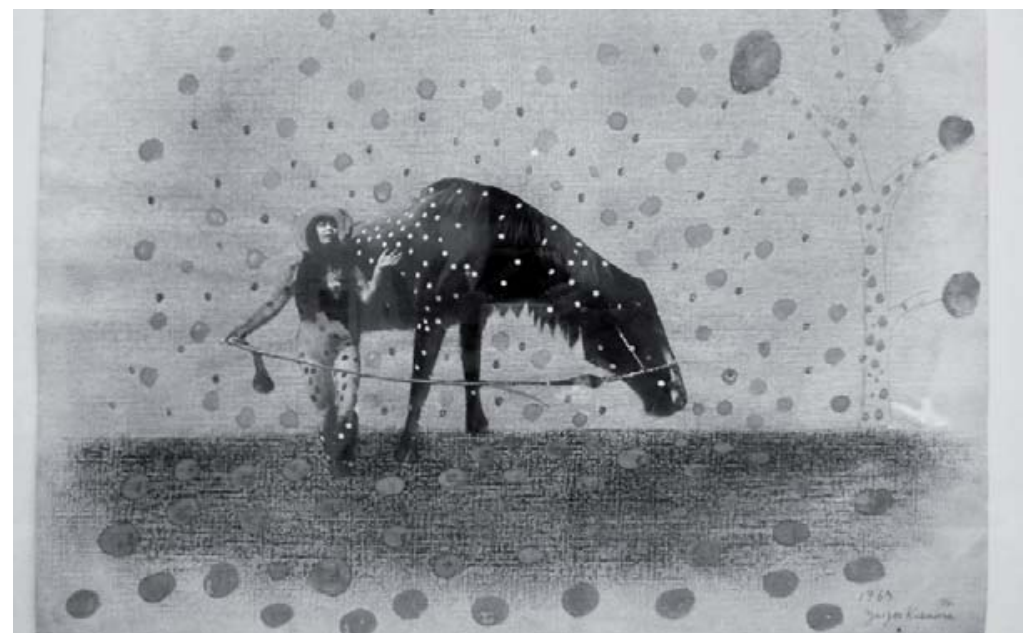

Fig.16. Representar el infinito a través de los puntos son una de las características de las obras de Yayoi Kusama. Imagen; Maria Jesús Abad Tejerina.
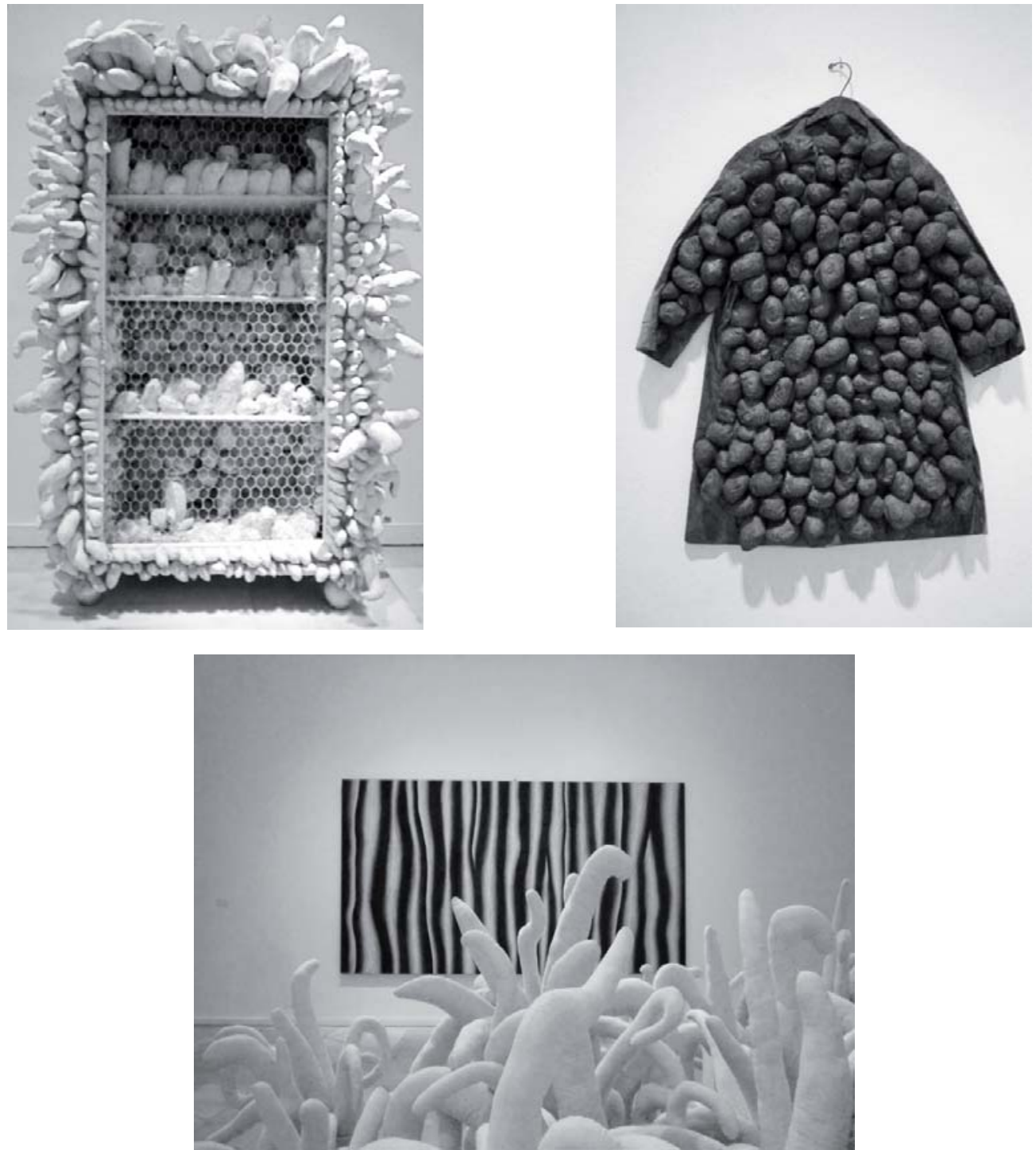

Fig.17,18,19. La acumulación y las formas tentaculares son otra de las maneras de reconocer su obra. Imagen: Maria Jesús Abad Tejerina. 

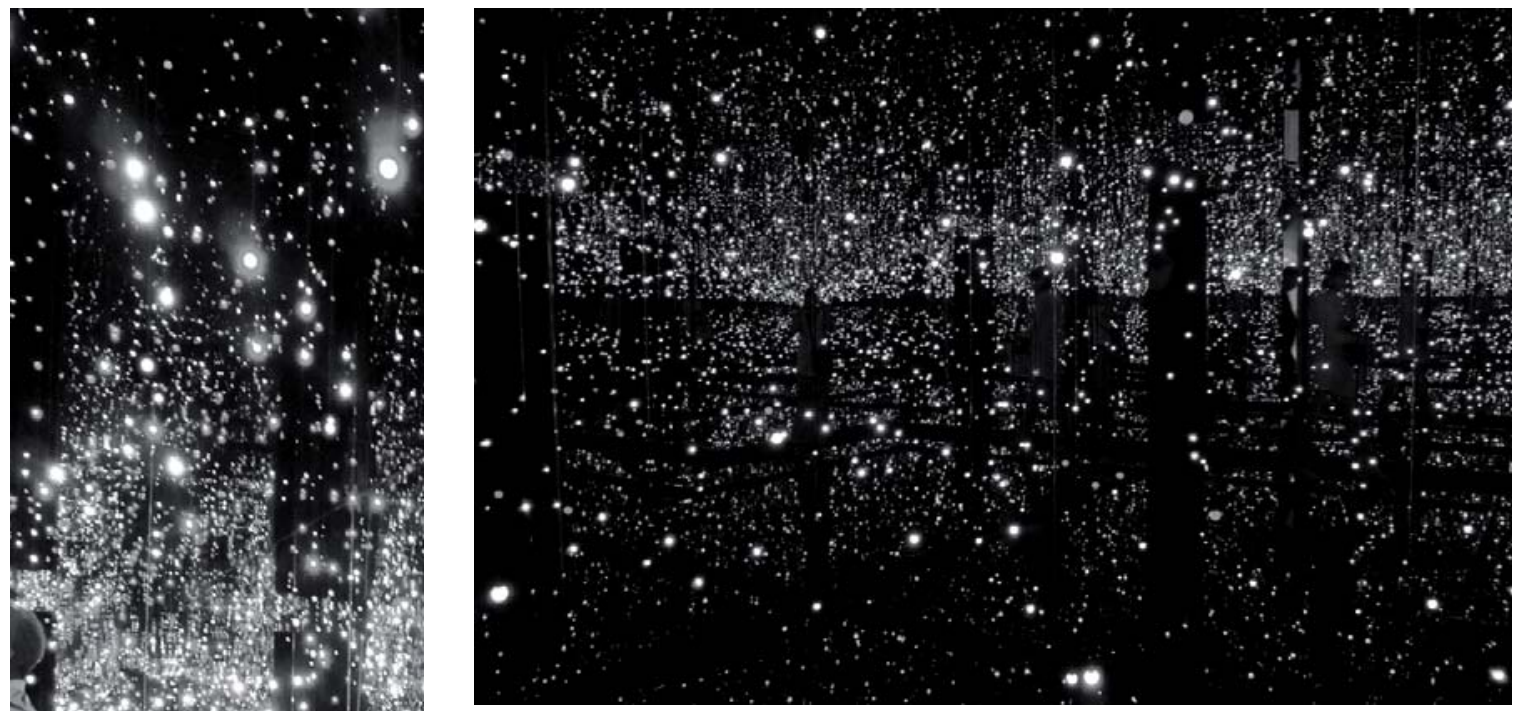

Fig.20,21. Hace instalaciones, esculturas, pinturas, performances, escribe, dirige cine.

Imagen: Maria Jesús Abad Tejerina.

\subsection{Bloque práctico: propuesta de trabajo}

¿Cómo se hace?

Para hacer una pecera basada "inspirada" en las piezas artísticas de Yayoi Kusaba necesitamos lo siguiente:
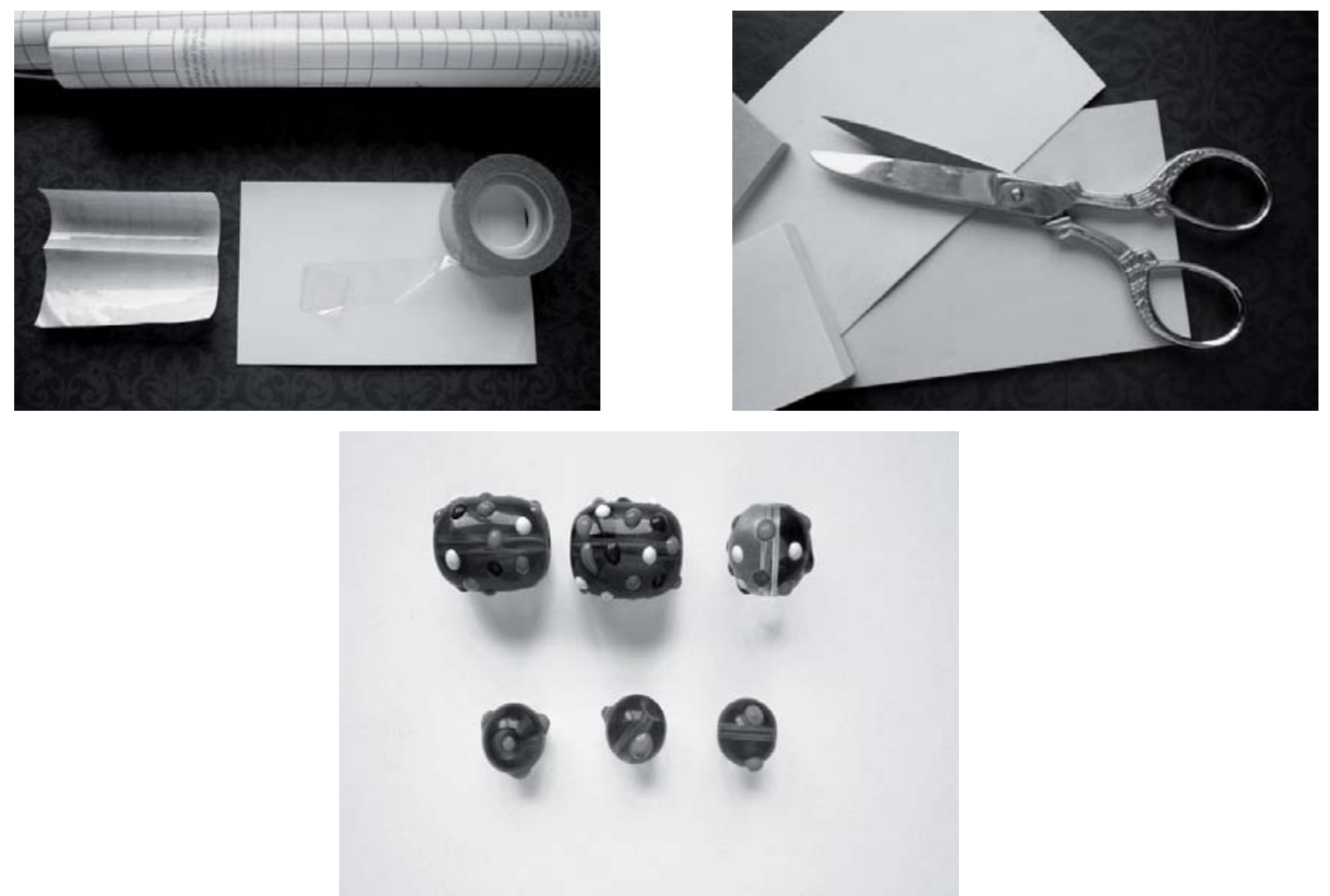

Fig.22,23,24. Papel adhesivo transparente, hojas de papeles de colores saturados y brillantes, bolitas de cristal que tengan un cierto peso (estas son de una pulsera adquirida en una tienda de las conocidas como “todo a 100") Imagen: Maria Jesús Abad Tejerina. 

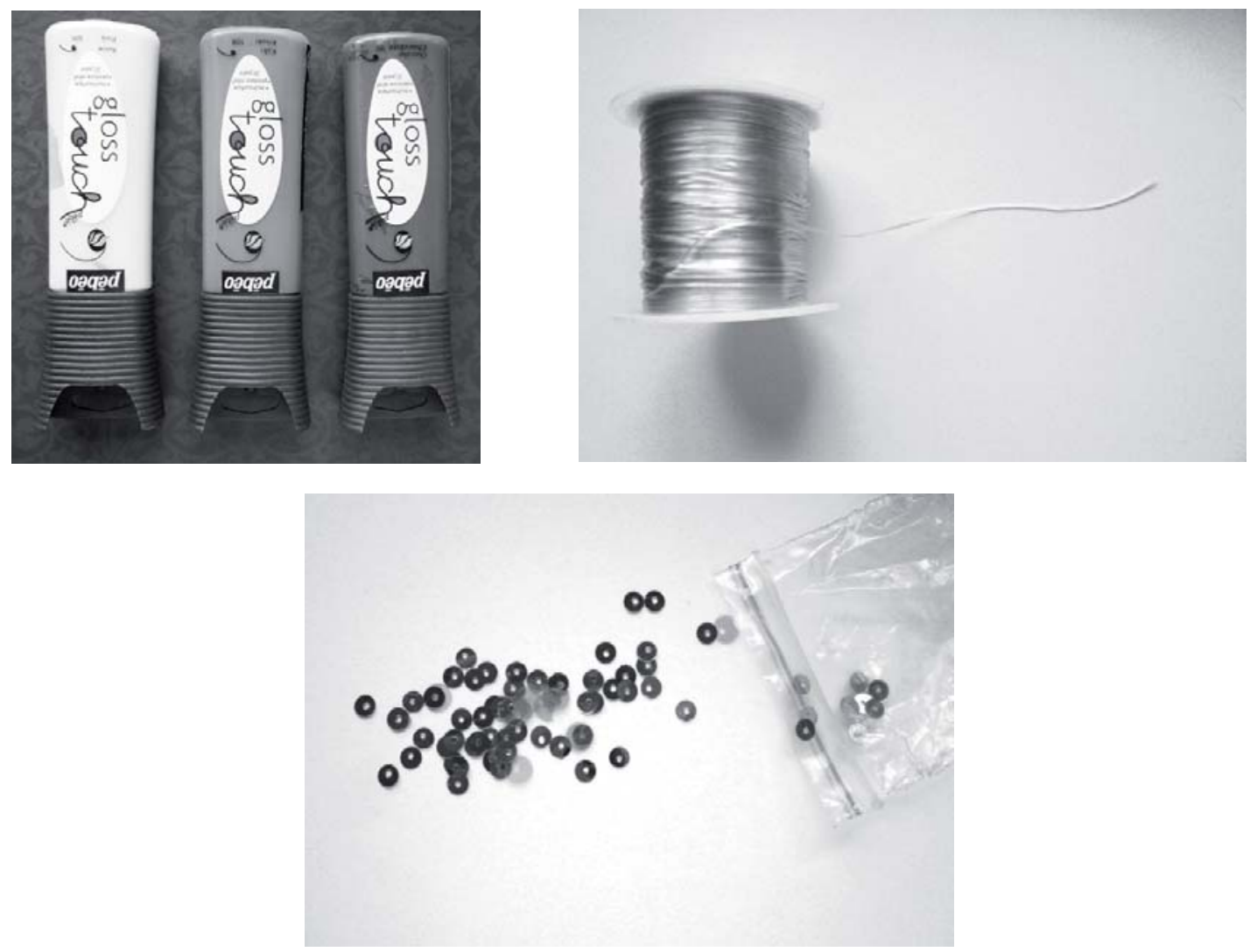

Fig.25,26,27. Pinturas de plástico con dispensador (para no tener que usar pinceles y poder cerrarlas cuando lo necesitemos) hilo de pescar o goma transparente, lentejuelas o circulitos de colores. También necesitamos: Cartones con el interior de espejo (o cualquier otro elemento que tenga ese efecto). Cinta adhesiva, taladradora de perforar papel y botellas o bolsas de suero desechadas. Imagen: Maria Jesús Abad Tejerina.
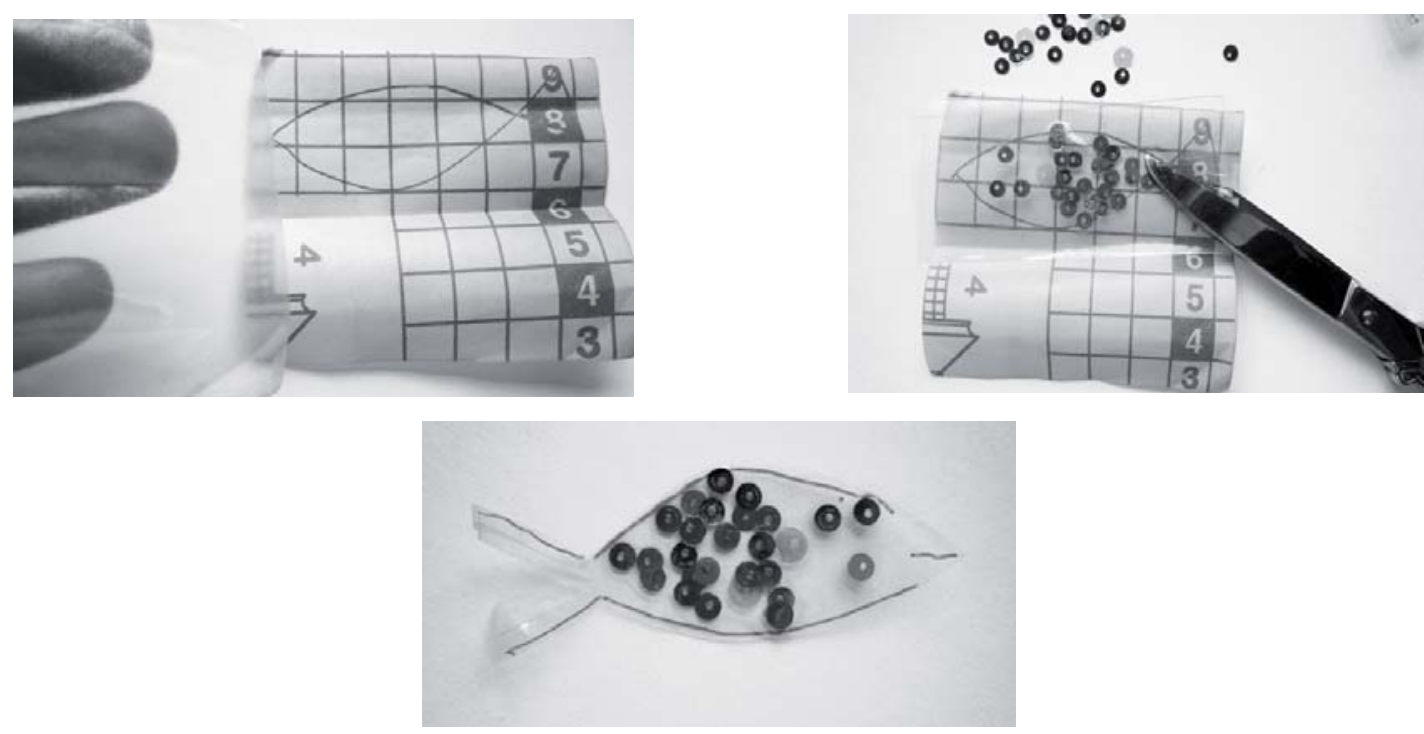

Fig.28,29,30. Dibujamos con rotulador permanente la forma de un pez proporcionado al tamaño de la bolsa. Retiramos el protector del adhesivo, colocamos lentejuelas o los lunares que quedan dentro de la perforadora de papel, pegamos las dos superficies adhisvas y recortamos con la forma del pez. Después perforamos la parte inferior de la figura para introducir el hilo al que atamos la bolita para que mantenga el pez a flote sin subir a la superficie. Hay que calcular la altura, medir antes o rectificar después. Imagen: Maria Jesús Abad Tejerina. 

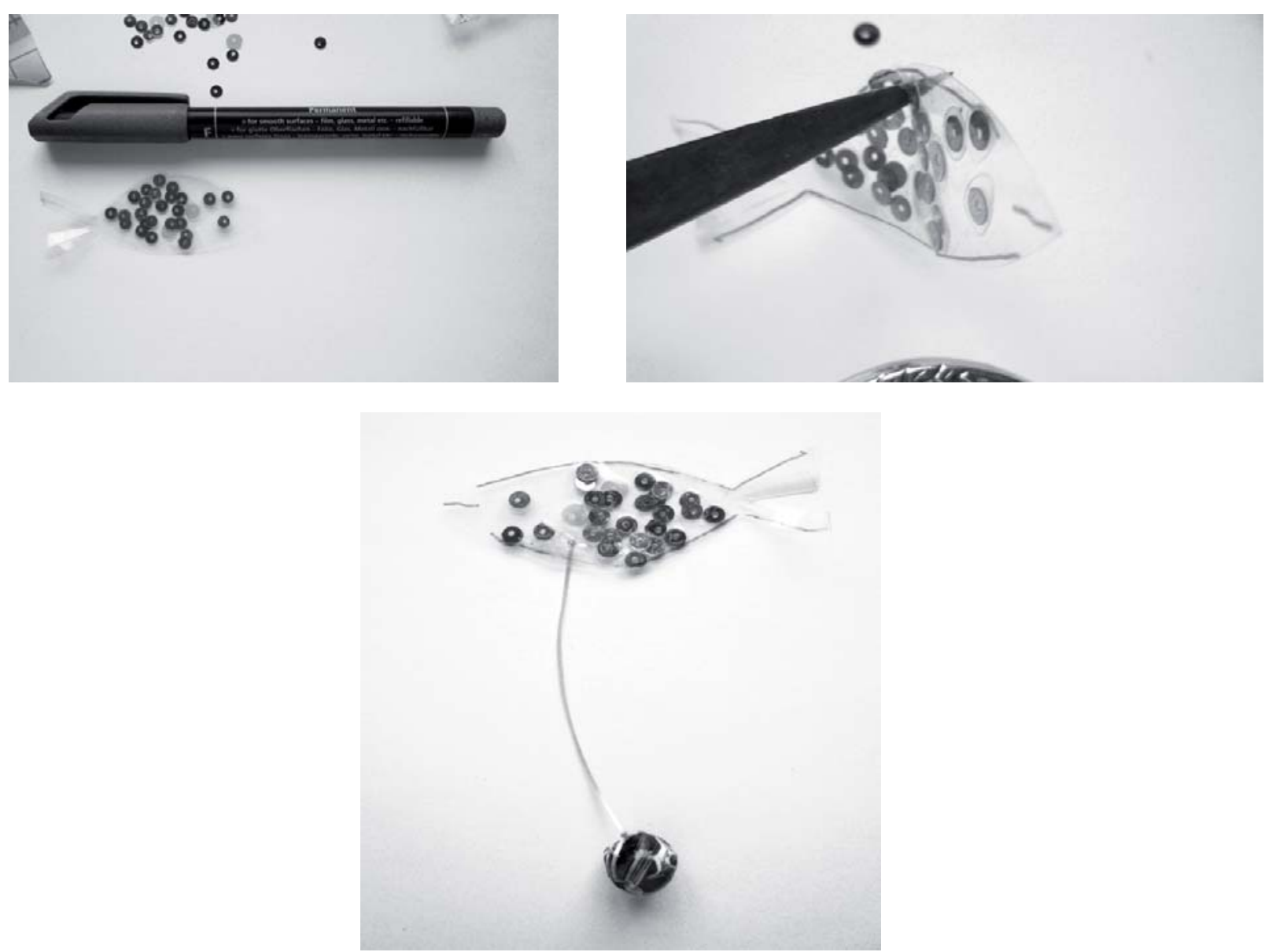

Fig.31,32,33. Vemos la consecución de los pasos señalados en el texto anterior. Imagen: Maria Jesús Abad Tejerina.
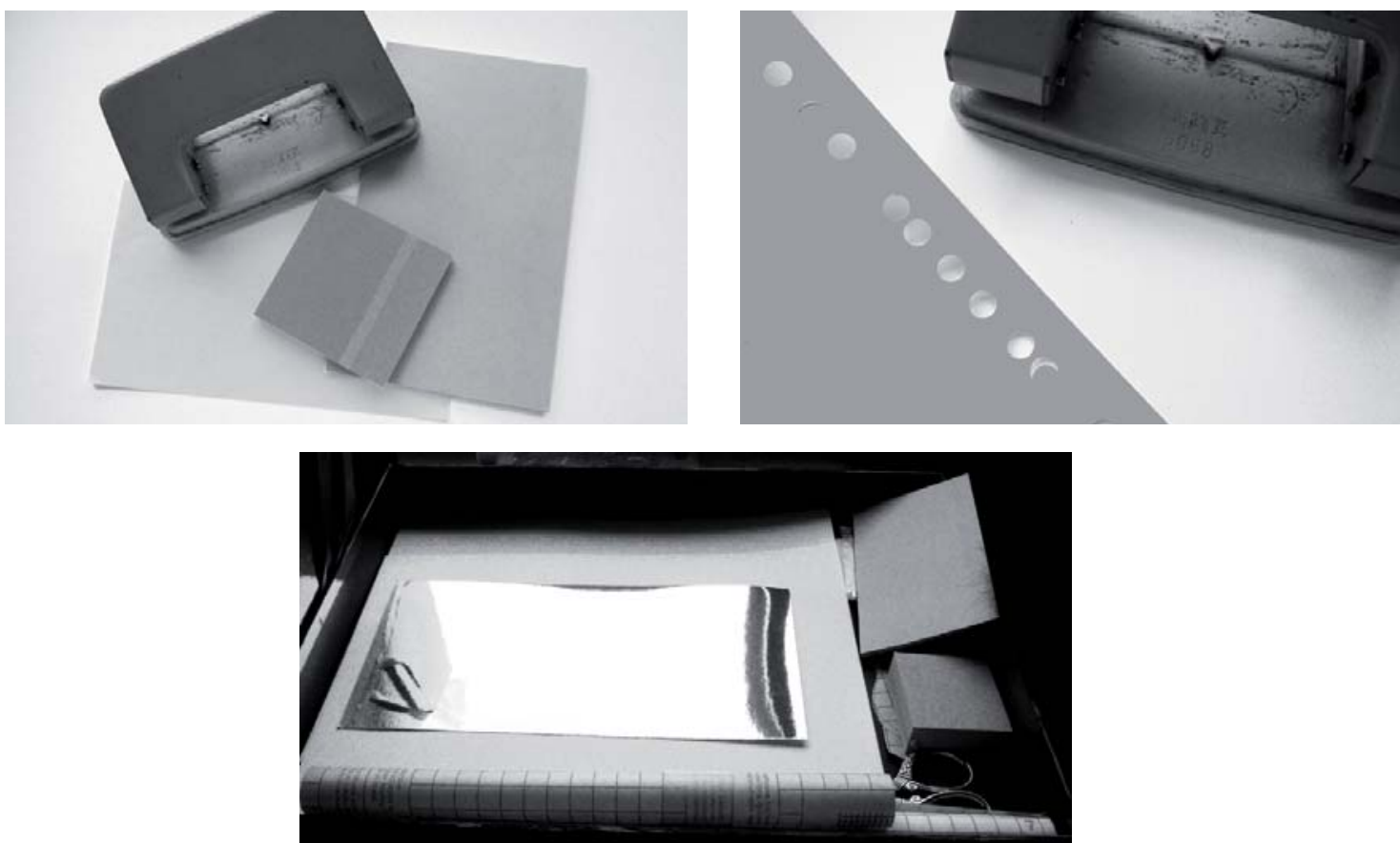

Fig.34,35,36. La taladradora y los papeles de colores fluorescentes, cartulina plastificada de espejo y un papel ya taladrado. En el depósito de la taladradora quedan los lunares que son los restos del papel. Imagen: Maria Jesús Abad Tejerina. 

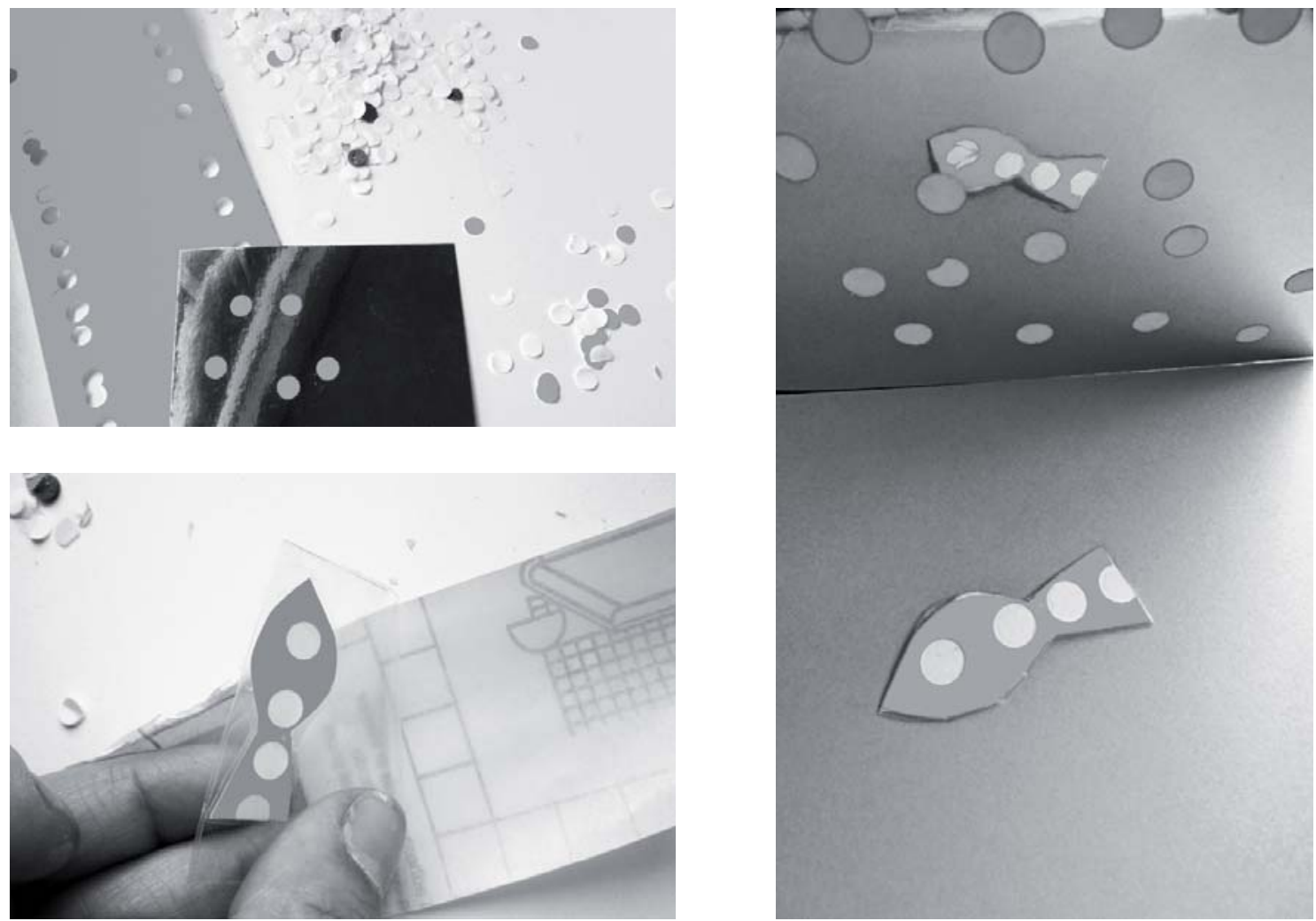

Fig.37,38,39. Pegamos los lunares al espejo y el papel taladrado lo usamos, en esta ocasión, para imitar las estrategias de Yayoi "figura fondo" tal como hace en las instalaciones.

Imagen: Maria Jesús Abad Tejerina.
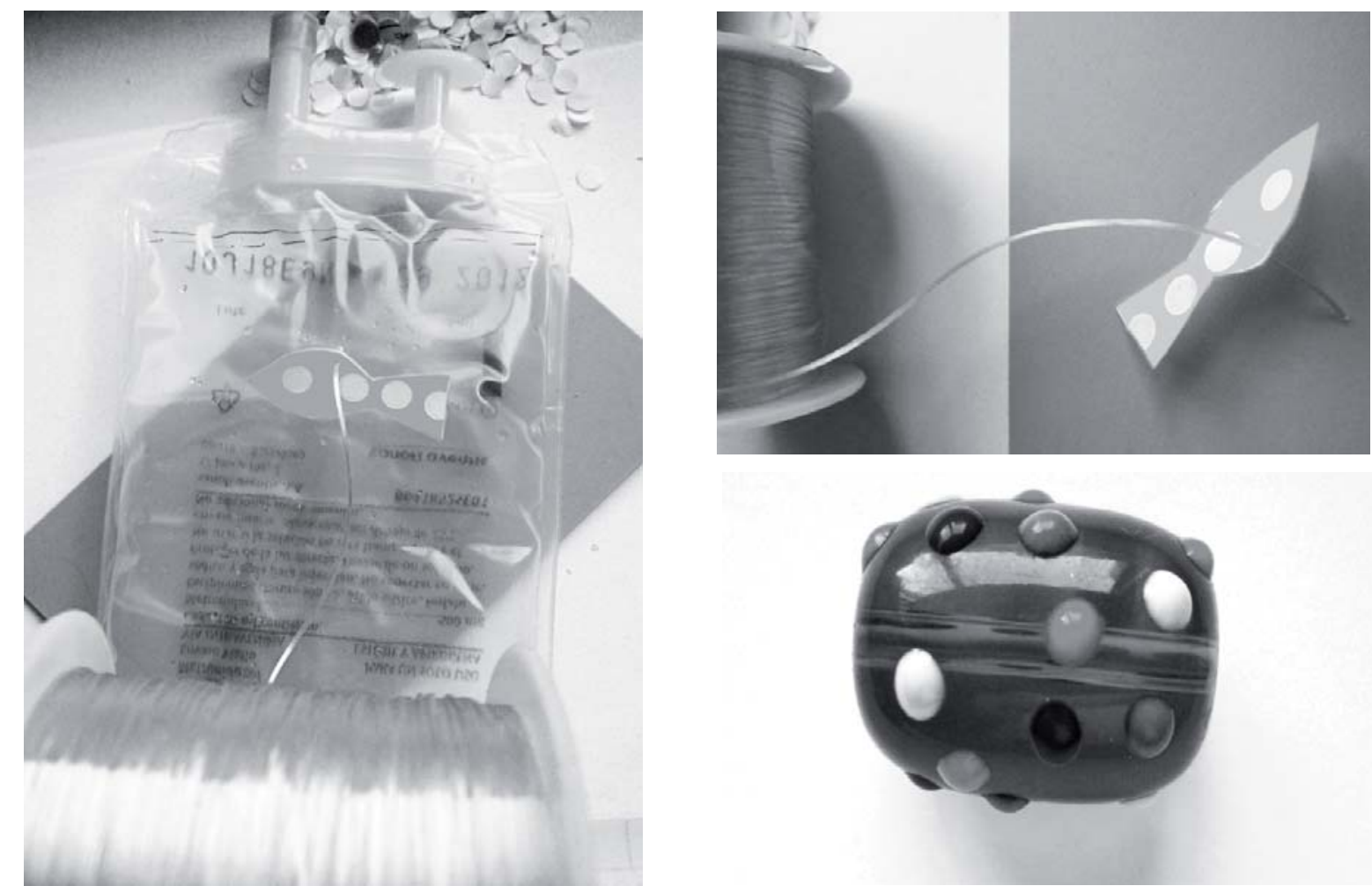

Fig.40, 41, 42. Plastificamos con cita adhesiva el pececito, le ponemos la bolita de cristal sujeta con el hilo. Imagen: Maria Jesús Abad Tejerina. 

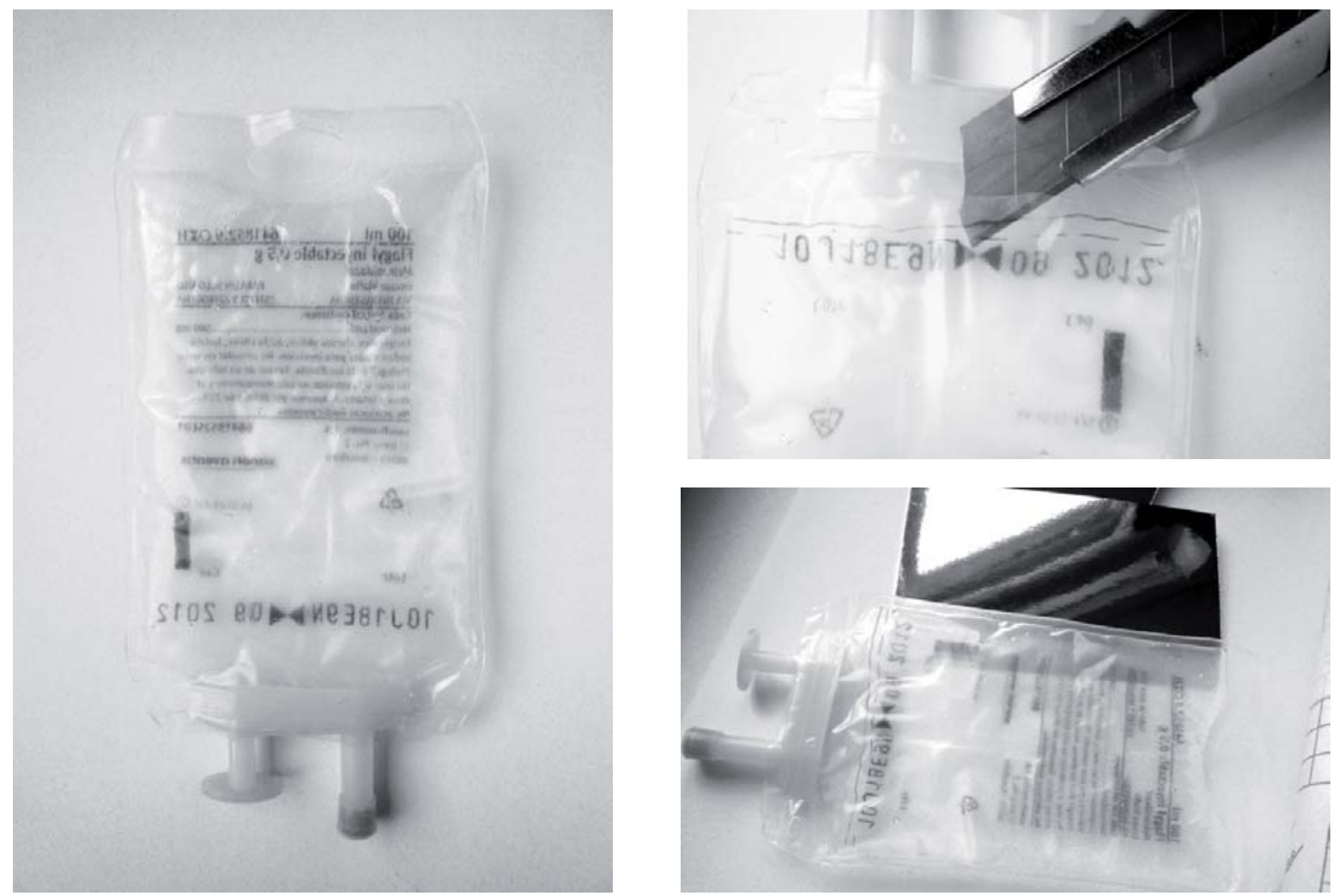

Fig.43, 44, 45. Con una cuchilla o tijera cortamos longitudinalmente la parte inferior de la bolsa de suero. Como las bolsas y botellas pueden ser diferentes, tenemos que fijarnos en colocarla de modo que una vez introducida el agua donde flotará nuestro pez y sellada con esparadrapo o cinta adhesiva no se salga el agua. También hay que desarrollar distintas formas de sujetar al árbol de medicación venosa la bolsa pues al quedar al revés no contamos con la perforación por la que normalmente se cuelga. En el caso de la muestra se sujeto con un pequeño alambre, pero se podría haber hecho con esparadrapo, vendas... Generalmente en los hospitales hay bastantes recursos y las enfermeras dispuestas a prestarnos un poco de ayuda. Imagen: Maria Jesús Abad Tejerina.
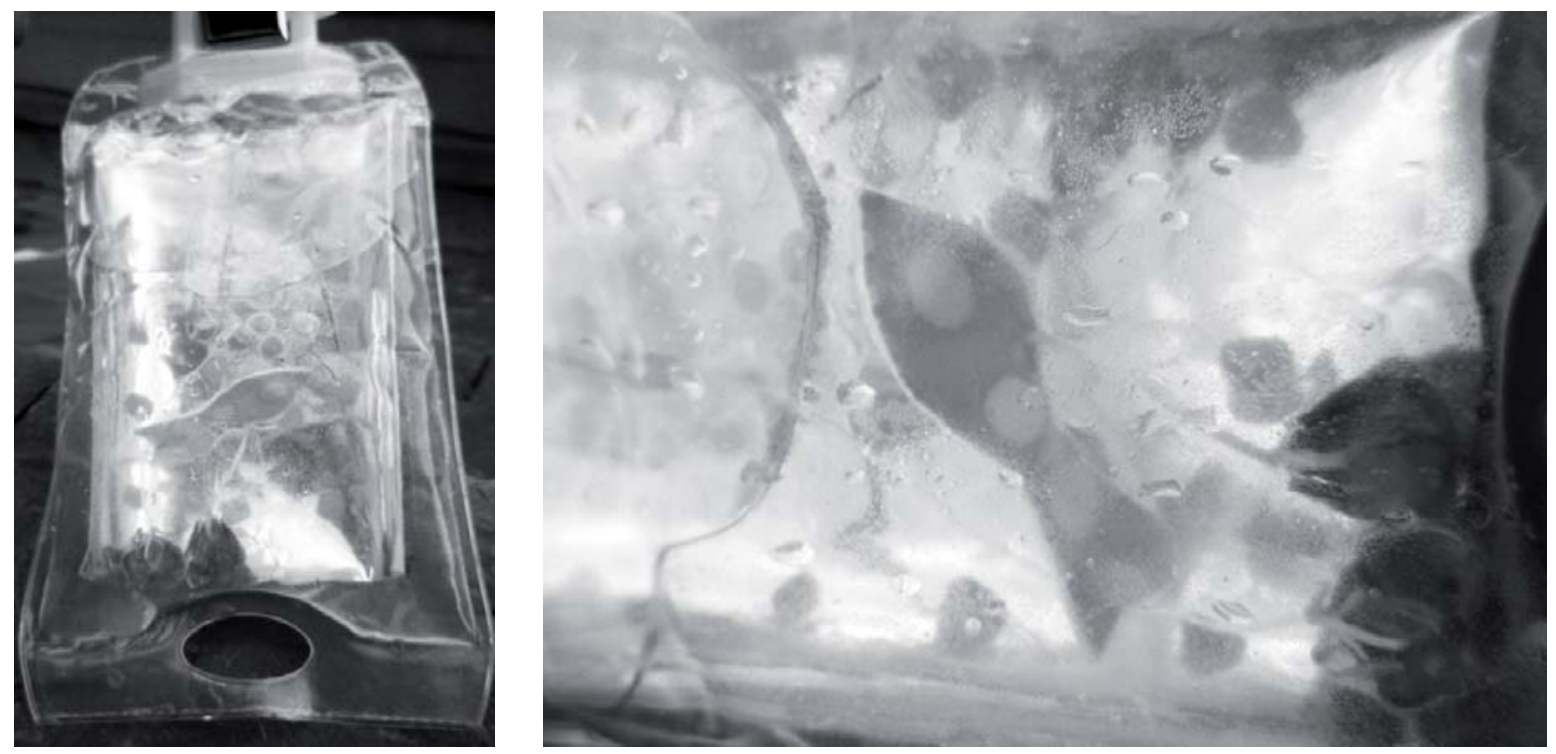

Fig.46, 47. Vemos en la Imagen el resultado de la pecera Yayoi. La bolsa que hemos elegido es posiblemente la más pequeña y la menos transparente. De modo que la imagen que mostramos como resultado final es fácilmente mejorable. Imagen: Maria Jesús Abad Tejerina. 


\subsection{Preguntas clave}

1. Debate anexionado a este discurso: ¿Se puede ser un gran artista estando hospitalizado?

2. Debate: ¿Cuántos movimientos artísticos en los que ha participado Yayoi conoces?

3. Debate: ¿Cómo se identifica el trabajo de un artista?

4. Debate: ¿Qué es más fácil: entender a los artistas actuales como Yayoi o a los clásicos cómo Velázquez?

5. Debate: ¿Cuáles son las diferencias entre una atracción de parque de atracciones y una instalación artística?

6. Debate: ¿Crees que tiene más valor hacer un cuadro o una escultura que una instalación?

\subsection{Conclusiones del taller Acuario "Yayoi"}

Las conclusiones a las que pretendemos llegar con la propuesta de este taller, se fundamentan en los objetivos de partida.

- Consideramos que puede mejorar la autoestima de los pacientes, utilizando el arte como medio para encontrar respuestas satisfactorias en forma de piezas artísticas. Todos conocemos el placer que produce crear algo nuevo y bello.

- Los asistentes tendrían la sensación de no perder el tiempo, debido a la duración de cada sesión de su tratamiento. Al disponer de un monitor que les acompaña y motiva, emplean su tiempo de forma positiva. Por otra parte, el estimular la creatividad para rentabilizar el tiempo de tratamiento podría ayudarles ayuda a sentirse mejor y el tiempo que antes consideraban perdido se transforma en conocimiento.

- las horas de taller se centraría la atención en el arte. Es una forma eficaz de redirigir el pensamiento - generalmente centrado en la enfermedad- hacia la acción y la búsqueda de la belleza.

- Una vez realizada la práctica, los alumnos podrían contemplar los materiales que les rodean con una mirada más atenta y aguda, creando nuevas conexiones mentales de modo que la capacidad creativa se ve estimulada de forma positiva estableciendo relaciones entre los materiales "reciclados".

- Está demostrado que cuando se abordan temas nuevos se enriquece el lenguaje visual. 


\section{Referencias}

Agliardi, A. 2010: I Disegno. Ed. Feltrinellikids. Milano.

Cerebro. 2006. Las Claves para la Educación. Ed. Ariel. Barcelona.

Carrillo, J. 2004: Arte en la Red. Ed Ensayos Arte Cátedra. Madrid. .

Grau, C. 2001: La pedagogía hospitalaria en el marco de una educación inclusiva. Ed. Archidona: Aljibe. 2001.

Michitaro, T. 2010: Karada el Cuerpo en la Cultura Japonesa. Ed. Adriana Hidalgo. Argentina.

Steiner, G., Y Ladjali, C. 2005: Elogio de la transmisión: Maestro y Alumno. Ed. Siruela.

WEB:

http://webinformacion.es/www.joanbrossa.org

http://www.barbarakrakowgallery.com/artists

http://www.chemamadoz.com/

http://www.elcultural.es/noticias/ARTE/1611/Yayoi_Kusama

http://hoyesarte.com/miradas/9849-yayoi-kusama-el-arte-de-la-obsesion.html http://www.artechilenoindependiente.cl/profiles/blogs/documentacion-yayoikusama 